\title{
La Visión del Mundo en los Cuentos de Enrique Anderson Imbert
}

Enrique Anderson Imbert ha escrito cuatro libros de cuentos, y en el prólogo de cada libro declara que su obra contiene una "visión del mundo"." Al prologar el último libro La locura juega al ajedrez el autor nos advierte además que, para entender esa visión central, será necesario leer la totalidad de sus cuentos (p. 1). Los cuatro libros, así, constituyen una serie de obras que circula alrededor de un solo punto central. Todo lo cual es curioso, y tal vez significativo, porque si podemos imaginar el círculo representado por la totalidad de los cuentos, el cuadrado formado por los cuatro libros, y todo esto alrededor del punto más importante en el centro, lo que tenemos es la imagen mental de una mandala. Para Carl Jung y la psicología moderna, la unión del círculo y la cuaternidad, representada por la mandala, produce el signo universal de la totalidad psíquica. ${ }^{2}$ En términos psicológicos, así, los cuentos de Anderson Imbert pueden considerarse como la expresión de la psique del autor.

Pero, ¿en qué consiste este imago mundi del cuentista argentino? No será fácil encontrarla, tratándose de un autor como Anderson Imbert cuya vasta cultura incluye, como se verá, elementos de literatura, historia, filosofía, teología, mitología. Al prologar su segundo libro de cuentos, El gato de Chesire,

${ }^{1}$ En dos ocasiones emplea la frase "mi visión de la vida": El grimorio (Buenos Aires, Losada, 1961), p. 8; y El gato de Chesire (Buenos Aires, Losada, 1965), p. 8. En La sandía y otros cuentos (Buenos Aires, Editorial Galerna, 1969), habla de una "concepción del mundo" (p. 7). Ultimamente, emplea la frase "mi visión del mundo" en La locura juega al ajedrez (México, Siglo XXI, 1971), p. 1. En adelante, los números de página corresponderán a las ediciones citadas. Para referirme al título de los cuatro libros, empleo el siguiente sistema de abreviaturas: El grimorio $=\mathrm{G}$; El gato de Chesire $=\mathrm{GC} ;$ La sandía $y$ otros cuentos $=\mathrm{S} ;$ La locura juega al ajedrez $=\mathrm{L}$.

${ }^{2 !}$ Según Jung, el círculo posee la característica de la totalidad a causa de su forma perfecta; la cuaternidad, porque cuatro es el menor número de partes en las cuales un círculo puede ser dividido naturalmente; véase C. G. Jung, Aion, en Collected Works of C. G. Jung, IX, 2 (Princeton, Princeton University Press, 1973), p. 224. También Juan Eduardo Cirlot habla de la importancia del Centro en relación con la mandala y la cuaternidad en su libro, A Dictionary of Symbols (New York, Philosophical Library, 1962), pp. 39-40 y pp. 192-193. 
el autor nos ayuda un poco al describir el contenido de la manera siguiente: "Mis cuentecillos son mónadas, átomos psíquicos en los que se refleja, desde diferentes perspectivas, la totalidad de una visión de la vida. De cifrarla, la palabra clave sería: libertad" (p. 8). Porque, aunque lo mencione solamente en el segundo libro, veremos que la esencia de los cuatro libros sigue siendo un concepto de libertad. Pero la libertad, al ser exagerada, conduce al caos, estado que exige el contrapeso de un concepto unitario que vuelva a juntar la multiplicidad de los elementos dispersos. Tornemos así al punto de partida y comencemos el estudio sistemático de unos temas principales que contribuyen a formar esta visión del mundo en la que se refleja la psique de nuestro autor.

\section{EL FRACASO DEL RACIONALISMO}

Se ha dicho que la fecha clave para el siglo veinte es el mes de agosto de 1914. En aquella fecha la Primera Guerra mundial surge para destruir las bases racionales de la sociedad occidental y, desde entonces, el hombre empieza a ver que gran parte de los valores que creía eternos se había desvanecido para siempre. Durante la primera parte del siglo presente, pues, ha ocurrido un cambio radical en la actitud del hombre hacia la razón. Por una parte, la razón no le ha ayudado a resolver sus problemas fundamentales $y$, por otra, el racionalismo exagerado-positivismo, pragmatismo, historicismo-de las épocas anteriores ha reducido la corriente vital del hombre a un cauce demasiado estrecho. Este es el momento en el que Unamuno clama: "Todo lo vital es antirracional, no ya sólo irracional, y todo lo racional, anti-vital." " Henri Bergson declara casi simultáneamente: "El intelecto está caracterizado por una natural incapacidad para comprender la vida." "4i Y José Ortega y Gasset continúa en la misma vena: "La razón es sólo una forma y función de la vida... Situada frente y contra la vida representa la subversión de la parte contra el todo. Urge reducirla a su puesto y oficio. El tema de nuestro tiempo consiste en someter la razón a la vitalidad..." ${ }^{5}$

Será evidente que Anderson Imbert también está muy consciente de los límites de la razón. Este es el tema central de muchos cuentos, y en su libro de ensayos Los domingos del profesor también se describe la futilidad de los autores realistas que tratan de copiar el mundo tal como es, porque "lo malo es que nadie sabe cómo es el mundo".

El género literario intelectual por excelencia es el de la novela policial o el cuento de detectives, donde el héroe suele ser un racionalista extraordinario. Tradicionalmente, la novela de detectives comienza con un misterio que se aclara poco a poco, hasta que todo se explica lógicamente al final. No ocurre de esta manera, sin embargo, en los cuentos policiales de Anderson Imbert. En estas

${ }^{3}$ El sentimiento trágico de la vida, en Obras Completas (Madrid, Afrodisio Aguado Editores, 1958), p. 161.

${ }^{4}$ Creative Evolution (New York, Modern Library, 1944), p. 182. La traducción al español es mía.

${ }^{5}$ El tema de nuestro tiempo, en Obras Completas (Madrid, Revista de Occidente, 1962), p. 178.

${ }^{6}$ Los domingos del profesor (México, Editorial Cultura, 1965), p. 5. 
obras vemos un proceso inverso, donde el empleo de la razón no resuelve nada, y a veces hasta sirve para aumentar el misterio. Por ejemplo, en "El crimen del desván" (G, p. 72), ocurre un asesinato, llega el detective, se les examina a los presentes, pero la solución del misterio no aparece. Al fin, una anciana pregunta: "¿Y si fuera algo sobrenatural?" Desde las alturas de su raciocinio, el detective responde sardónicamente: "¿Sobrenatural?... No hay nada sobrenatural" (p. 73). Entonces se oye una gran carcajada y todos los personajes se convierten en pálidas llamas que se van acercando hasta fundirse en una sola transparencia. No hay una solución lógica, porque todo es magia, hecha por un duende aficionado a novelas policiales. De la misma manera, el detective de "Murder" (L, p. 89), aclara el misterio del crimen, pero su razón no le permite ver que él mismo será una víctima del asesino. Y en "La bala cansada" (G, p. 196), el bibliotecario Jorge Greb se describe como un "intelectual puro" que está aficionado a novelas policiales. Procura anular la realidad, convirtiéndola en un cuento de detectives, pero al fin está obligado a reconocer la validez de los hechos irracionales cuando está destituido de su puesto en la biblioteca. El narrador comenta entonces con suma ironía: "¿Qué mala suerte! Bueno, consolémonos: a lo mejor Jorge Greb, cesante, tuvo más tiempo para terminar su cuentito" (p. 205).

El tema del racionalismo fracasado no se limita, por supuesto, al cuento de detectives. En "Dos pájaros de un tiro" (S, p. 79), el protagonista Hansen es un razonador maniático que tiene la "enfática manera de clasificarlo todo en series paralelas"; también es "un esgrimista que para los ataques y contrataca con lógica de acero". Pero el pensar tan lógicamente le causa un problema, cómo él mismo reconoce: "la inteligencia a veces se me enferma y entonces no produce ideas espontáneas, sino ideas fijas" (p. 89). Todo empieza cuando Hansen conoce a dos mujeres y entra en una situación que no corresponde a su manera de ordenar la vida según la lógica. Porque ni Virginia - fea, salvaje e inteligente-, ni Elena-bella, sensual y tonta-corresponde a la visión de un mundo ordenado. Por eso, Hansen decide destruir a los dos "pájaros" - Elena y Virginia - con un solo "tiro"; decide cometer un crimen, un acto irracional, que destruye a las dos mujeres y a él mismo.

Un caso semejante ocurre en "La norteamericana" (G, p. 136); Ena Winthrop es una mujer "fría, intelectual", a quien le gusta estudiar a los hombres con "algo de método científico" (p. 137). Lo que más quiere de los hombres no es el amor ni el placer, sino oírlos hablar para poder analizar sus reacciones y, por supuesto, sentirse superior a ellos. Todo le va bien hasta que llega a la Argentina y se encuentra con Felipe Cruz. Cruz es un matemático mestizo, hombre cuyo origen humilde le ha obligado a tener en cuenta sus emociones, a ser algo más que un puro intelectual. Ena, como siempre, pone en movimiento su plan de coqueterías científicas, para encontrar al Gran Hablador. Así, cuando Cruz entra en su cuarto al final y la viola sin hablar, representa el triunfo de la emoción sobre el intelecto. Ella y su ciencia están humilladas por un hombre que ella consideraba su inferior. 
El aspecto anti-vitalista del racionalismo es evidente en muchos cuentos y, especialmente, en el que se intitula "Porvenir" (GC, p. 47):

Era de veras alarmante. Los hombres estaban cubriendo con substancias duras la superficie de la tierra: pavimientos de piedra o asfalto, ciudades de altos edificios apretados unos contra otros, máquinas que andaban por el campo aplastándolo todo, selvas taladas, ríos entubados, redes de subterráneos, cañerías de hierro y cemento, escombros y basuras de lata y loza enterradas en el subsuelo, cascos de metralla y bombardeo clavados muy hondo.

- Tengamos un poco más de paciencia - una hierba dijo a otra, desde la juntura del embaldosado en un patio humilde-. Los hombres no van a durar mucho. Después volveremos, con los bosques capitanes. La "substancia dura", que representa el producto de la tecnología moderna, arruina la textura más suave de la vida natural. Pero el hombre tecnológico no va a perdurar, a pesar de la dureza de sus creaciones. La civilización basada en la razón no puede nada contra la espontaneidad permanente de la Vida.

\section{LA DESINTEGRACION DE LAS FORMAS TRADICIONALES}

Con el derrumbamiento de las instituciones racionales, vuelve a aparecer la visión de un mundo caótico, visión que siempre ha quedado latente debajo de la superficie de la consciencia del hombre civilizado. Desde la época de los griegos antiguos, el hombre ha tratado de ordenar la vida de acuerdo con un rigoroso sistema de conceptos absolutos producidos por la razón. Pero, como un monstruo que dobla su cuerpo para devorarse a sí mismo, la razón crea situaciones im. posibles $\mathrm{y}$, poco a poco, se destruye a sí misma. $\mathrm{Y}$, con la ruina de la frágil estructura de las supuestas "verdades absolutas", todo es posible. Si "nadie sabe cómo es el mundo", los productos de la fantasía irracional son tan válidos como los de la conciencia racional.

\section{El absurdo}

El absurdo, como resultado del fracaso del racionalismo, campea temiblemente en el mundo literario de Anderson Imbert. Basta mencionar unos ejemplos. "El estructuralista Duclaux" (L, p. 176), presenta el extraño caso del "gran Jean Duclaux" (¿Levi Strauss?) que descubre "el secreto de la Gran Estructura", basándose en la única palabra - "quoi"-que sabe pronunciar su extraordinario hijo Pataud. El relato termina de la manera siguiente:

Asombrado por el parecido entre el genio y el idiota, le pregunté tímidamente:

- ¿Pató?

- Cua-me contestó.

Salimos. Por las calles Pató me iba explicando París:

- Cua, cua, cua... (pp. 177-178).

En "El príncipe" (G, p. 243), se ofrece el espectáculo de una ruidosa fiesta nacional para celebrar el nacimiento del nuevo heredero del rey. Con tanto 
estrépito, el recién nacido se muere. $\mathrm{Y}$ un sentimiento de horror ante un mundo que ya no obedece a las leyes naturales se da en "La granada" (GC, p. 16), cuando un niño irrumpe en el comedor y grita: "¡Mamá, mamá, ahí viene una orquídea!"; entonces todos los ojos se fijan en el vano de la puerta. La realidad que se presenta en esto y en muchos otros relatos no se presta a un análisis lógico. El absurdo ha entrado en la fábrica misma de las leyes naturales, y el antiguo orden de los conceptos absolutos ha sido sustituido por un orden nuevo, donde predomina la Teoría de la Relatividad y el Principio de Indeterminismo.

\section{La realidad al revés}

Alicia, protagonista de "Los duendes deterministas" (G, p. 12), llega al país de los duendes, yendo en busca de uñ milagro. Se le pregunta cómo llegó allí y contesta: "No sé. Lo que a nadie se le hubiera ocurrido, eso preferí yo. Así, haciéndolo todo al revés, llegué a este monte" (p. 15). Estas palabras nos dan una buena descripción de la conducta del mismo Anderson Imbert, porque él también prefiere hacerlo todo al revés, imaginando situaciones que a nadie le hubieran ocurrido. Por eso, abundan en su obra situaciones donde se observa una inversión de las leyes naturales. En "El leve Pedro" (G, p. 9), la ley de la gravedad funciona al revés y el protagonista "se cae" al cielo. "El cigarillo" (G, p. 83), presenta una extraña situación en la que un cigarillo fuma un hombre. En "Microscopía" (G, p. 235), un hombre crece en sentido inverso a la normalidad y se disminuye hasta desaparecer por completo. El héroe de "Don Juan y el tiempo" (GC, p. 150), se hace cada vez más joven-hombre, mancebo, puber, rorro, crío, feto-, hasta que acaba en un óvulo.

Otro aspecto de la realidad al revés es el concepto del "pluriverso", según el que hay otro universo que paralela al nuestro en sentido inverso, como el reflejo de un espejo. En "La antorcha" (GC, p. 20), un hombre blanco que lleva una antorcha va a una reunión del Klu Klux Klan. Cuando entra en un callejón tenebroso y cree oír pasos a su lado, se asusta y deja caer la madera ardiente. Entonces un negro aparece en la oscuridad, recoge la antorcha caída y se le ofrece al blanco, empuñándola "por el lado de la llamarada". Semejante situación se presenta en "Bestiario" (GC, p. 72), cuyo protagonista atraviesa una puerta milagrosa en medio del desierto y entra en un trasmundo donde viven unicornios, dragones, hipogrifos. Entonces ve un rinoceronte y le parece una bestia "quimérica". No hay una realidad única en la obra de Anderson Imbert, sino una multiplicidad de realidades posibles. Lo mítico existe junto a lo histórico; lo fantástico, junto a lo real.

\section{El tiempo}

Puesto que vida y tiempo son inseparables, la alteración de la realidad tradicional no puede menos de producir cambios radicales en el concepto del tiempo. En un mundo desordenado, donde las leyes físicas pierden su vigencia, es de esperarse que el tiempo pierda también su carácter irreversible. Veamos primero la causa de este nuevo concepto temporal. 
Desde el momento primordial cuando el hombre se hizo consciente por vez primera del carácter transitorio de su existir, también ha tenido gran importancia la idea de las cosas que perduran. Aparece así uno de los conflictos fundamentales de la vida, entre el tiempo y la eternidad. Para muchas personas el elemento más importante de la vida siempre ha sido el tiempo fugitivo. En la obra de Anderson Imbert, no obstante, también importa mucho el concepto de la eternidad.

Uno de los cuentos más importantes para entender la visión de nuestro autor es "Instantáneo" (GC, p. 50), una pequeña obra maestra que contiene muchos de los temas que nos interesan en el estudio presente. El asunto es sencillo: un hombre anda por la playa y piensa en la naturaleza del mundo físico. Entonces una mujer sale del mar y le dice que el mundo y el tiempo son productos de la conciencia humana: "Sin conciencia, todo el mundo se apagaría en una inmutable y simultánea masa... Nuestra conciencia inventa las cosas y hace que formen filas, esperen y pasen lentamente, una detrás de otra. Todo esto se daría de una sola vez por todas, en un solo instante, si no fuera porque tú y yo y los demás lo obligamos a retardarse o a acelerarse" (p. 51). Poco después la mujer desaparece y el protagonista reconoce haber perdido su concepción materialista del mundo. Se desnuda gozosamente y se echa a nadar, mar adentro. Si aceptamos esta explicación solipsista de la realidad, pues, significa que la duración temporal pierde su importancia, porque el tiempo es sólo un producto de nuestra conciencia. Si la única realidad es la de nuestro "yo" y todo lo demás es invención, todos los momentos temporales existen simultáneamente: el pasado y el futuro solamente existen porque los imagina el "yo" presente.

La idea de la simultaneidad de los instantes temporales se relaciona estrechamente con otro concepto importante en la obra de Anderson Imbert: el concepto jungiano de la conciencia colectiva. José, de "El hijo pródigo" (G, p. 41), declara a su hermano Daniel: "Todos los hombres son un hombre solo... Los hombres de ayer, de hoy, de mañana, todos, todos, somos un mismo hombre" (p. 49). Si todos los hombres-pasados, presentes y futuros-son un solo hombre, todos los tiempos también se confunden en un solo Tiempo: pasado y futuro son solamente otras perspectivas de un presente eterno. Compárese todo esto con la manera en que Jung describe el inconsciente colectivo:

Si fuera posible personificar la subconciencia, podríamos definirla como un ser humano colectivo que combina las características masculinas y femeninas, que trasciende la juventud y la vejez, el nacer y el morir, y, porque tiene a mano la experiencia humana de uno a dos millones de años, es casi inmortal. Si existiese tal entidad, sería por sobre todo posible cambio temporal; el presente le importaría ni más ni menos que cualquier año del siglo céntimo antes de Cristo; sería la soñadora de sueños milenarios $y$, a causa de su experiencia inmensa, sería pronosticadora incomparable. Habría vivido incontadas veces la vida del 
individuo, de la familia, de la tribu y de la gente, y poseería el sentido vivo del ritmo de crecimiento, de floración y de decadencia.?

De esta manera, pues, se explica lo que ocurre en "Amistad" (L, p. 151), donde el protagonista revela que el origen de su novela es un mito arquetípico: "lo que hizo fue abrir la boca y por su boca habló la memoria ancestral de la especie, el inconsciente colectivo, la conciencia mítica en una edad mítica, un arquetipo impersonal asentado en el fondo de la materia nerviosa" (p. 158); "Todos los hombres son un solo héroe de innumerables caras que lleva siempre la misma máscara y representa su papel de mitómano en el gran teatro del mundo" (p. 159). . Idéntica situación se observa en "La locura juega al ajedrez" (L, p. 162), cuando Blanco quiere jugar al ajedrez y, estando solo, busca un segundo jugador en las profundidades de su propia inconsciencia: "Se hundió en el recuerdo de sus pesadillas y alucinaciones, se fundió en la memoria ancestral de la especie y allí encontró los mitos de seres desdoblados y dioses bicéfalos" (p. 166). Alli es donde encuentra a Negro - su "sombra", en términos jungianos -y juntos entablan un largo partido de ajedrez que se remonta al principio del tiempo.

Así, la inconsciencia de un solo hombre contiene la memoria de la raza entera. Más aún. Si la conciencia colectiva abarca la totalidad de la historia, ya se hace posible el antiguo sueño de los escritores de ciencia ficción: se puede viajar en el tiempo, por medio de los sondeos en la inconsciencia. Y de esta manera volvemos a la afirmación de que en la obra de Anderson Imbert el tiempo pierde su carácter irreversible y se hace cada vez más libre y abierto.

Esta nueva libertad temporal aparece como tema central de muchos cuentos; en "Amok" (G, p. 240), por ejemplo, Santiago se enloquece y apuñala a un niño, a una vieja y a un labrador. Cuando recobre la lucidez, espera que vengan a llevarlo a su propia muerte, pero no ocurre de esta manera:

...Quien vino fue un ángel.

- Has hecho mal, pero no ha sido culpa tuya. Vamos a remediarlo ¿quieres? Ahora corre para atrás, sobre tus propias huellas. Al pasar, toca a tus víctimas: se pondrán de pie y vivirán como si nada hubiera pasado, sin recordar tu puñal. Borrarás así tu historia de sangre.

Así.lo hizo. Desanduvo su carrera, anuló el tiempo... (pp. 240-241). Y no solamente ocurren saltos hacia atrás; en "QQué voy a hacer yo con una guitarra?" (L, p. 27), el profesor Macedonio Fernández viaja al futuro donde aprende una nueva manera de escribir. Y el presente puede servir como punto de partida de un movimiento en dos direcciones a la vez. En "Vertigos" (GC, p. 32), dos monjes oyen el canto de un "pájaro maravilloso". Mientras canta el pájaro, Jerónimo ve trescientos años de historia hacia atrás en el tiempo. Cuando vuelve al presente, no encuentra a su compañero y describe su experiencia en una crónica. Teodoro, por su parte, salta al porvenir, donde un pintor lo usa como

${ }^{7}$ C. G. Jung, "The Basic Postulates of Analytical Psychology", en Modern Man in Search of a Soul(London, Harcourt-Brace, 1933), p. 215. La traducción es mia.

${ }^{8}$ Cf. Joseph Campbell, The Hero of a Thousand Faces (Cleveland, Meridian, 1963). 
modelo para un cuadro: "cuadro sobre un monje que, según una multisecular leyenda legada por un cronista llamado Jerónimo, había desaparecido del convento, volando por los aires, trescientos años atrás”. Se crea así la situación paradójica y circular en la que un hombre sirve como modelo para un cuadro de sí mismo, es decir, para el hombre de hace trescientos años.

Los conceptos de la simultaneidad del tiempo y la conciencia colectiva son necesarios también para explicar la idea del eterno retorno que sirve como base temporal de la novela Fuga y de varios cuentos como "El grimorio" (G, p. 90), "Navajazgo en Madrid" (S, p. 55), y "Viento Norte" (L, p. 18). El último relato presenta la historia cíclica de un embrollo de tiempos, según el que "todavía en el pasado cierto presente fue ya un futuro" (p. 29). Un argentino cuenta a un escritor inglés una historia que había oído en Buenos Aires: dos hombres reciben un misterioso aviso de un homicidio y entonces, cuando se encuentran poco después uno de los hombres mata al otro, tal como se había avisado. El círculo se aumenta vertiginosamente cuando se descubre que esta historia repite el asunto de un cuento del escritor inglés y que éste, a su vez, había imitado a varios escritores antiguos, para expresar la idea de un mito griego: "Un cuento sale de otro...y ése de uno anterior; y así hasta los orígenes, en la mitologia" (p. 32).

\section{El solipsismo}

La idea de que la realidad está creada por las percepciones de la conciencia humana fue expuesta por el irlandés George Berkeley en el siglo XVIII y, con la pérdida de fe en la concepción racionalista del mundo, vuelve a aparecer en ciertas obras del siglo veinte. ${ }^{9}$

En la obra de Anderson Imbert, el solipsismo es uno de los factores principales que contribuye a destruir el concepto de la realidad tradicional. La descripción más completa de la creación por medio de la conciencia se encuentra en el ya citado relato "Instantáneo". Al hablarle al narrador de su creencia en la existencia independiente de un mundo material, la mujer le aconseja: "Observa mejor la gran mirada que crees arrojar al exterior. La llevas siempre prendida por dentro: es como una de estas olas, que parecen soltarse para cabrillear por playas y acantiladas pero nunca se separan del mar" (GC, p. 50). Aunque lo creemos fuera de nosotros, el mundo físico debe su existencia a la intención creadora que lleva cada hombre en su interior. Así es que sin conciencia, sin esa "locura metafórica" que el hombre siempre emplea para crear el mundo, todas las cosas "serían una y la misma cosa negra e inmóvil", porque "nuestra conciencia inventa las cosas" (p. 51). Cuando la mujer desaparece inesperadamente "sin dejar una sola huella", como si su conciencia se cancelara a sí misma, el narrador teme

\footnotetext{
"Todos los llamados "Seth Books" de Jane Roberts se basan en la idea de que el hombre crea su propia realidad: "You must understand that no objective reality exists but that which is created by consciousness. Consciousness always creates form, and not the other way around"; Seth Speaks (New Jersey, Prentice-Hall), p. 18. Véanse también The Seth Material, pp. 111-123; y The Nature of Personal Reality, pp. 76-84. Los libros de Carlos Castaneda, que se basan en las enseñanzas de don Juan Matus, contienen semejante idea: véase especialmente Journey to Ixtlan (New York, Simon and Schuster, 1972), Cap. 19, "Stopping the World".
} 
por un instante que, sin esa conciencia que lo apoya, todo el mundo también pueda desaparecer. Pero entonces reconoce su propio poder creador: "Me di cuenta de que si las cosas continuaban como antes era porque yo, que estaba allí en cierto modo sustituyendo a la muchacha, también llevaba dentro una burbuja de conciencia" (pp. 51-52).

La misma "locura metafórica" del hombre sigue inventando cosas en muchos otros cuentos de Anderson Imbert. En "La muerte del agua" (G, p. 60), el narrador describe el patio de un hotel en una tarde calurosa y afirma: "Sólo yo estaba allí y el patio existía porque yo lo miraba. Los demás huéspedes habían huído a sus celdas o al vestíbulo umbroso, olvidados de esta parte del hotel a la que mi atención impedía deshacerse en la nada." "En la pedana" (GC, p. 49) ofrece el caso paradójico de dos esgrimistas que se anulan mutuamente: "En el abismo abierto entre esos ideales espejos, las fintas de asalto se cancelaban repetidamente. Una noche ellos mismos se cancelaron y la sala quedó vacía" ( $p$. 50). Y el solipsismo también tiene un aspecto positivo: si el hombre inventa el mundo con su conciencia, significa que inventa también las leyes que lo controlan y puede rechazarlas, $u$ olvidarlas, adquiriendo asi una nueva libertad. Por eso, en "Esquemas de lo posible". (GC, p. 84), "Samuel se olvidó de que, por ser hombre, no podía volar: brincó para coger un higo, siguió subiendo por el aire y se perdió en una nube."

\section{Dos motivos simbólicos}

$\mathrm{Al}$ examinar los modos literarios que Anderson Imbert utiliza para presentar la desintegración del mundo que resulta del fracaso de la razón, se destacan dos motivos de valor simbólico: el subterráneo y el agua. Como veremos, ambos motivos apuntan a una vida donde el intelecto está sustituido por las potencias irracionales.

a. El subterráneo. La idea de la vida debajo de la tierra se remonta a los tiempos antiguos: ocurre en la mitología y vuelve a aparecer en el Infierno de Dante, en el episodio de la Cueva de Montesinos en el Quijote y en obras más modernas como Memorias del subsuelo, de Dostoieski, y El túnel de Ernesto Sábato. La permanencia de esta imagen, según Jung, se debe al hecho de que corresponde a una "imagen primordial", al arquetipo de la madre, el que se asocia a la inconsciencia donde reinan las emociones, los instintos, la intuición. ${ }^{10}$ Cuando el hombre es incapaz de funcionar bajo la luz de la razón, huye a la seguridad instintiva del seno maternal, a la caverna oscura de las emociones primordiales. ${ }^{11}$

\footnotetext{
${ }^{10}$ Para Jung, los simbolos de lo subterráneo- la caverna, el abismo, el pozo, la oscuridad, etc. - . se asocian al arquetipo de la madre. Pueden tener un sentido positivo o negativo, pero cuando representan la seguridad maternal, se relacionan con la autoridad mágica de la mujer, la sabiduría y la exaltación espiritual que trasciende la razón; véase "Psychological Aspects of the Mother Archetype", en Collected Works, IX," 1, pp. 81-82.

${ }^{11}$ Cirlot escribe que la idea de la caverna representa la seguridad y la invulnerabilidad de la inconsciencia; Op. cit., p. 38.
} 
El personaje andersoniano que mejor ejemplifica este escape del mundo claro de las formas es el protagonista deformado de "La muralla" (G, p. 114). Con el cuerpo grotesco de un niño de ocho años, este hombre trabaja para el circo y es feliz, mientras no tenga que mostrarse ante los ojos de la gente normal. Un día, sin embargo, está obligado a vestirse de payaso y a pasearse ante los niños. A causa de esto se enloquece y mata un hombre. Se encuentra ahora en un manicomio, rodeado de una muralla "blanda y gorda" que lo envuelve suavemente "sin apretar", dándole una grata sensación de seguridad uterina. Más allá de la muralla, no obstante, sigue amenazándole el vasto espacio del mundo abierto: "QQué abismo, el de la luz! Las nubes ofrecían sus colchones mullidos; pero si uno saltaría sobre ellas se desgarrarían como telarañas y el cuerpo seguiría cayendo hasta estrellarse en un fondo duro y azul. Bajó la vista, con vértigo, y se acurrucó en el suelo" (p. 114). Y además del terror que le causa la visión de los espacios abiertos, también sufre la angustia de la luz "Cerró otra vez los ojos. No quería ver el patio, no quería ver la luna. Aun el aire de la noche, que era como un bálsamo para las llagas que abre el sol, lo trastornaba" (p. 115). Por eso cava un laberinto de túneles oscuros debajo del manicomio: "iQué placer, arrastrarse como un gasterópado, sintiendo a sus espaldas la gran concha del edificio!" (p. 115). Cuando el túnel pasa por debajo de la muralla y el enano cava hacia arriba para orientarse, rechaza la libertad, y vuelve a la matrix de la muralla: "Retrocedió en el subterráneo...y cavó otra vez, ahora debajo de los cimientos mismos de la muralla. Era lo que siempre había querido: comunicar su laberinto con la muralla, abrirle una vena hasta que pudiera, de noche, pasear libremente por todo el manicomio" (p. 117). Psicológicamente, el cuento describe un caso de agorafobia-el miedo de atravesar los espacios abiertos-, junto con el deseo freudiano de volver a la protección del seno maternal. Simboliza la inseguridad metafísica del hombre ante la visión de un mundo caótico, sin sentido. El tamaño reducido del personaje representa la insignificancia del hombre en un universo enorme, y su temor a la luz representa la tendencia a evitar la verdad demasiado penosa que nos muestra la razón.

El símbolo del subterráneo no siempre es negativo, sin embargo, porque a veces, como dice Jung, el descenso a las profundidades de la inconsciencia precede a un ascenso a las alturas del espíritu. "12 A sí ocurre en "La |torre" (G, p. 87): Solness quiere construir la más alta torre del mundo, pero antes hay que cavar un absimo en "las esponjosas entrañas de la tierra" y colocar allí un cimiento que soporte el peso. Con obreros y grúas se hunde en la tierra, siempre pensando en las estrellas. Un día les soprende la muerte, pero todo no está perdido, porque "en aquel nicho sombrío y con olor a grisú murieron todos en la punta de una torre al revés, lustrosos como semillas" (p. 88). La torre al revés puede interpretarse como un símbolo fálico; penetra las "esponjosas entrañas" de la tierra madre, dejando allí las lustrosas semillas de una nueva vida espiritual.

${ }^{12}$ Jung, "The Archetypes of the Collective Unconscious", en Collected Works, IX, 1, p. 19. 
b. El agua. Varios escritores han señalado la importancia del agua en la obra de Anderson Imbert. Para Valentín J. Gaivironski, el agua en su obra "posee una complejidad simbólica", cuyo "ámbito es el indefinido del ensueño". "Isabel C. Ruíz declara que el elemento líquido "es empleado...en sus versiones de mar, río, lluvia, para significar el vaivén y la calidad huidiza, y hasta cierto punto fantasmal, con que se pueden presentar personas, cosas y aun recuerdos." ${ }^{14} \mathrm{El}$ agua es un símbolo femenino, y es considerada como principio y fin de todas las cosas. Mircea Eliade ve en el agua un símbolo de la disolución de las formas, pero también, fuente y origen - fons et origo-de todas las existencias posibles. ${ }^{15} \mathrm{Para}$ J. E. Cirlot, la inmersión en el agua significa una vuelta al estado preformal, seguido a veces por un acto de renacimiento y regeneración. No renace el hombre físico, sin embargo, sino el del espíritu, porque, para la psicología moderna, el agua - representada por el mar-es un símbolo de la inconsciencia (Jung), y por eso se relaciona con la sabiduría intuitiva ${ }^{16}$ También Gaston Bachelard afirma que "ver en el agua es como ver en el alma"."

Todo esto es aplicable a la obra de Anderson Imbert, donde el motivo del agua se asocia en muchos cuentos a la desintegración y a la libertad intuitiva. En "Instantáneo", el mar se presenta, tal como en el simbolismo tradicional, como principio y fin de la vida. La mujer solipsista que destruye el materialismo del narrador emerge del mar. Luego, cuando el narrador se echa a nadar "mar adentro", significa la muerte del hombre racional. Pero el lector también ve en este acto simbólico una vuelta al estado preformal del cual renacerá el nuevo hombre espiritual cuyo poder intuitivo va a crear el mundo.

$\mathrm{Al}$ estudiar otros relatos, veremos que el agua también se presenta, como el símbolo del subterráneo, ya como una fuerza negativa-muerte y disolución-, ya como una fuerza positiva-regeneración espiritual, libertad intuitiva-. Veamos primero el aspecto negativo.

"El viaje" (G, p. 109) ofrece un ejemplo notable de la disolución total por la inmersión en el agua. El protagonista es un adolescente frágil y seco, tiene ojos "sin brillo ni humedad" y su cuerpo está "a punto de deshacerse como un terrón". La falta de agua representa el distanciamiento de los orígenes femeninos, lo cual crea una tensión, una falta de equilibrio que, cuando se exagera como en el caso presente, puede producir resultados trágicos, como

\footnotetext{
${ }^{13}$ Valentín Jacobo Gaivironski, "La narrativa de Enrique Anderson Imbert”, Nueva narrativa hispanoamericana, I, 2 (1971), pp. 111-112.

${ }^{14}$ Isabel C. Ruíz, "Anderson Imbert, autor de ficciones" en Homenaje a Enrique Anderson Imbert, editado por Helmy F. Giacomán (New York, ANAYA, 1974), p. 130.

${ }^{15}$ Mircea Eliade, The Sacred and the Profane (New York, Harcourt-Brace, 1959), p. 130.

${ }^{16}$ Cirlot, Op. cit., p. 345. Para ver las ideas de Jung en cuanto al símbolo del agua y su relación con la inconsciencia, véanse Aion, Collected Works IX, 2, p. 142; y "The Archetypes of the Collective Unconscious", Collected Works, IX, 1, pp. 18-19.

${ }^{17}$ Gaston Bachelard, La poétique de la reverie (París, Presse Universitaires de France, 1965), p. 172. La traducción al español es mía.
} 
presagia el'narrador: "Bajo el cielo bobo parecía un montoncito al que una lluvia violenta disolvería en barro" (p. 109). Indicativa de su falta de equilibrio es su obsesión por el mar: "¿Qué pobre parecía allí arriba el cielo azul...! Cielo duro, duro... Lo flúido era el mar" (p. 110). También siente la poderosa atracción de una muchacha, la que "tenía un mar en los ojos" (p. 111). Pero, aislado y distante en su fealdad, no se atreve a acercarse, y corre para esconderse en el agua. Se deja llevar por las olas y, cuando intenta volver, no puede. Angustiado por su soledad, flota en el agua hasta que "las carnes se le fueron disolviendo en el mar, como un terrón" (p. 113). En este relato el mar representa, como la imagen del subterráneo en "La muralla", el arquetipo de la madre que le ofrece al hombre un refugio donde puede ahogar su sensación de soledad. Cuando entra en el mar, regresa al estado preformal que precede a la existencia física. En este caso no hay una sugestión de regeneración espiritual, sino de muerte y desintegración. "El aire y el hombre" (G, p. 36) presenta una situación semejante, donde la fuerza devoradora del aire también está descrita con imágenes acuáticas.

En otros cuentos más optimistas el motivo del agua se asocia a la idea de la libertad intuitiva. En "Los duendes deterministas", por ejemplo, el agua se emplea para reforzar la idea de la creación mágica. Y el poder de la intuición representado por el agua se presenta poéticamente en "Diario" (GC, p. 105):

Salgo al jardín. Todo está duro: suelo de cerámica, árboles de piedra, flores de cera, aire de cristal, cielo de porcelana. Duro. Todo duro. Pero basta una mariposa para enternecer el temple del universo. Es una mariposa que se ha posado en el sendero, con las alas plegadas. La tierra es ahora flúida como el mar; y la mariposa, una barca de grandes velas.

La intuición poética, representada por la mariposa, disuelve la dureza material en un mar de fluidez. De este mar primordial, nacen-o renacen-todas las cosas.

Antes de pasar a otra cosa, conviene examinar también la importancia del pez, otro símbolo que forma parte del simbolismo del agua. Para J. E. Cirlot, el pez puede representar el poder intuitivo de la inconsciencia. ${ }^{18}$ También se asocia históricamente el signo de Pisces, último signo del Zodíaco, formado por dos peces que nadan en direcciones opuestas. Cirlot nos dice que este signo está estrechamente ligado al simbolismo del agua y a la disolución de las formas. Cuando se transpone, por analogía, al plano psíquico, a causa de su mutismo y su inconsciencia denota frustración, exilio y seclusión. ${ }^{19}$ Este último atributo nos recuerda la alienación del protagonista de "El viaje", cuando flota en la soledad del mar y piensa en la época cuando todos los hombres "éramos peces" (GC, p. 112). También Jorge Greb, el bibliotecario solitario de "La bala cansada" es "frío como un pez, solemne como un pez" (G, p. 197). Y en "El hijo pródigo", se

\footnotetext{
${ }^{18}$ Cirlot, Op. cit., p. 101.

${ }^{19}$ Ibid., p. 244 .
} 
emplea la misma imagen para describir la indiferencia de un Dios que no se preocupa por los hombres: "Elohim se iba por las timieblas como un tremendo pez acuático, lleno de sí mismo y sin curiosidad" (G, p. 53).

Por otra parte, la relación entre el pez y la capacidad intuitiva es evidente en obras como "Los duendes deterministas", donde el Reo Primero, a quien le condenan por ejercer sus poderes mágicos, se compara a un "pez en el fondo de ese océano de aire" (G, p. 17). En "Luna", cuando Jacobo roba la torta, salta "con la alegría de un salmón" y desaparece volando sobre las chimeneas de la azotea" (GC, p. 49). También en "Vigilancia" (GC, p. 152), se habla de un negro que anda "con un pescado colgado al cuello". Piensan que es loco y ciego, pero es que ha aprendido a "ver" con los ojos cerrados" "Ya lo sabes pues: cuando lo veas con los ojos cerrados es que te está vigilando, cuando lo veas con los ojos abiertos es que está dormido". Los ojos abiertos, cuando el negro está "dormido", representan los límites de la conciencia racional. La imagen del pez, en cambio, simboliza la presencia del poder intuitivo, el cual no necesita la luz de la razón para "vigilar" las cosas.

Con esto, terminamos el estudio de la desintegración del mundo racional en la que se enfoca la "visión" de Anderson Imbert. Queda ahora estudiar una doble consecuencia de esta desintegración para la vida del hombre.

\section{EL HOMBRE LIBERADO}

Ya lo ha dicho el autor: la palabra clave de su visión del mundo es "libertad", y en efecto todos los temas estudiados hasta ahora pertenecen a una vida abierta y flexible, donde el hombre es tan libre como su imaginación. El símbolo principal que Anderson Imbert emplea para representar este estado de libertad es el vuelo mágico, símbolo que resulta, como se ha dicho, en una notable imagen bifronte: "la de un enamorado del aire y la de un escritor disgustado con la ley de la gravedad". ${ }^{20}$ Piénsese, por ejemplo, en el caso de Jacobo, en "Luna", el que utiliza la magia para robar la torta y entonces sigue su vuelo por los aires en una poderosa afirmación de la capacidad intuitiva del hombre.

El mito de Icaro, pues, cobra gran importancia en la obra de Anderson Imbert. Y como es de esperarse, en el relato que se intitula "Icaro" (GC, p. 55), el autor presenta su propia interpretación del mito griego:

Dédalo no comprendió nunca a su hijo, el imaginativo Icaro. No lo comprendía al verlo imitar los movimientos de animales terrestres. Tampoco lo comprendía cuando, volando juntos - cada quien con su par de alas bien sujetas a los hombros-el muchacho lanzaba chillidos de pájaro. Mucho menos lo comprendió - ¡creyó que se caía porque el sol había derretido la cera de las plumas!-cuando Icaro, cansado ya de jugar a pájaro, se desprendió de sus alas y, alegremente, se precipita de cabeza al mar para renovar su juego y ahora ser pez.

Dédalo es el racionalista que siempre busca una explicación lógica para todos los

${ }^{20}$ Alejandra Pizarnik, "Sabios y poetas", en Homenaje, p. 210. 
sucesos; por eso, fracasa en su intento de comprender el espíritu libre de su hijo. Icaro, en cambio, es el intuitivo que, satisfecho por el acto de ejercer su libertad en el mundo de las formas, decide sumergirse en las profundidades de la inconsciencia, simbolizada aquí otra vez por las imágenes del mar y el pez. El mito demuestra así la importancia del libre empleo de la intuición cuando se trata de establecer una relación, tan importante para la psicología, entre la conciencia y la inconsciencia. Solamente de esta manera el hombre puede completarse y llegar a la totalidad de su ser. ${ }^{21}$

Y no vuelan solamente las criaturas animadas: en "Vuelos" (GC, p. 122), todo el mundo vuela, literalmente, como lo saben muy bien el árbol y el monte, los cuales se ríen del pajarito que se asusta de ver tanta cosa inmóvil: "Sentían muy por abajo, allá por las raíces y por las rocas, el temblor de un gran vuelo: itoca la Tierra volaba y ese pajarito, dele que dele a las alas, no lo sabía!'(p. 124). El pájaro representa otra vez al típico racionalista que fija su atención solamente en las formas aparentemente inmóviles y no está consciente de las profundidades, donde vuelan las intuiciones. Lo cual nos recuerda el caso del olmo, de "Ambición" (GC, p. 37), el que envidia el vuelo de los pájaros: "Ante tanto cielo, ante tanto ejemplo de libertad, la ambición del olmo era volar. Se erguía, estiraba los brazos. Un día le creció un nuevo brote. No era un brote cualquiera: era una pluma. Una pluma verde. El comienzo de una ala." Como dice Bergson, "la conciencia es sinónima a la libertad", y donde hay conciencia, todas las cosas pueden "volar".

Finalmente, el concepto de la libertad también está reforzado por la presencia del rebelde que se niega a aceptar los límites del mundo concebido por la razón. De ahí que los duendes "anti-deterministas" se opongan a las restricciones intelectuales impuestas por el rey; y en "Luna", cuando el farmacéutico quiere imponer un orden de verdades científicas, Jacobo lo destruye con su vuelo fantástico ${ }^{23}$ Hasta el ciclo de repeticiones causado por el eterno retorno tiene una salida; no es un círculo cerrado porque, en último término,

${ }^{21}$ Jung habla también de ciertos ritos de renovación espiritual, donde uno de los elementos simbólicos es el agua que representa la fuente y origen de la vida. Entonces sigue a decir lo siguiente: "The rites are attempts to abolish the separation between the conscious mind and the unconscious, the real source of life, and to bring about a reunion of the individual with the native soil of his inherited, instinctive make-up." Todo esto es importante, porque la mente consciente representa solamente una parte del selbst total: "In my experience the conscious mind can claim only a relatively central position and must accept the fact that the unconscious psyche transcends and as it were surrounds it on all sides. Unconscious contents connect it backwards with physiological states on the one hand and archetypal data on the other. But it is extended forwards by intuitions which are determined partly by archetypes and partly by subliminal perceptions depending on the relativity of time and space in the unconscious"; Dream Symbolism in Relation to Alchemy, en The Portable Jung, editado por Joseph Campbell (New York, Viking Press, 1971), pp. 386-387.

${ }^{22}$ Creative Evolution, Op. cit., p. 287.

${ }^{23}$ Para una discusión más completa del conflicto entre la razón y la intuición en "Los duendes deterministas" y en "Luna", el lector puede consultar mi artículo, "Respuesta a Sócrates: dos cuentos de Enrique Anderson Imbert", en Homenaje, pp. 293-306. 
pueden introducirse variaciones nuevas. Así, el protagonista de "Un navajazgo en Madrid" (S, p. 55) se siente atrapado en una serie de hechos que van a repetir el acto violento de una novela de Carlos María Ocampos, pero al final se niega a aceptar el desenlace trágico. Y en "Pusilanimidad con mayúsculas" ( $L, p$. 179), el protagonista va a Madrid con la intención de asesinar a Perón y, cuando llega el momento de ejecutar su proyecto de violencia, se siente atrapado en el mecanismo impersonal del tiempo cíclico. Se rebela entonces ante esta amenaza a su individualidad y decide no matar al dictador:

Se acostó, encogiéndose en la postura del feto en la matriz... Cerró los ojos y murmuró:

- Mañana temprano arrojo el revólver en una alcantarilla y me vuelvo a Buenos Aires. No es que me haya acobardado. Creo que no... Lo que pasa es que no quiero caer en funciones de máquina. No sólo en el espacio de una ciudad, sino también en el tiempo de la historia, hay mecanismos de repetición. Yo perdería mi singularidad si me convirtiera en uno de los innumerables Brutos que han dibujado, en el aire de las crónicas, la Vasta Forma del Tiranicidio.

Con incredulidad, con resignación, con alivio su singularísima alma se durmió (pp. 183-184).

Vuelve al origen de su vida, no para anonadarse en la oscuridad de la psique colectiva-es contra esto que se rebela-, sino para recobrar la libertad de su alma individual, esa libertad esencial de la que todo hombre puede disfrutar, si no la sacrifica en el altar del miedo y el egoísmo. posibilidad que se estudiará en la siguiente sección de este trabajo.

\section{EL HOMBRE ATRAPADO}

En el mundo de los cuentos de Anderson Imbert, no hay ninguna garantía absoluta de libertad. A veces el hombre está cogido por un destino cruel, fuera de su control, como el protagonista de "Oscurecimiento en Nueva York" (G, p. 29), el que está atrapado contra su voluntad, en el sueño de otra persona. Con más frecuencia, sin embargo, es el hombre que se atrapa a sí mismo, al elegir el curso de su existencia, porque la verdadera libertad significa que no hay nada que lo obliga a ser libre. Y aunque no sacrifique la posibilidad de elegir su existencia, tampoco tiene la seguridad de elegir bien: a veces se equivoca y entonces tiene que aceptar las consecuencias de su error. Primero veremos la situación que resulta de la decisión de privarse, voluntariamente, de la posibilidad de ejercer la libre voluntad.

\section{El sacrificio de la libertad}

Hay, desde luego, una estrecha vinculación entre el racionalismo exagerado y la falta de libertad. Cuando se insiste en la soberanía de las verdades absolutas, el resultado es un concepto de predeterminismo, de "esencia antes de existencia", que destruye la vitalidad del ser humano. Cabe preguntar, sin embargo, ¿por qué algunas personas quieren sacrificar su libertad a la diosa de la razón? La respuesta se refleja claramente en los "ojos azules" del loco en "El dedo" (GC, p. 
152). Estos ojos claros ven con demasiada lucidez un mundo que, desde el punto de vista de la razón, es un enorme caos. Como en "La muralla", el resultado es la agorafobia y la consecuente necesidad de tocar con el dedo las paredes que representan la seguridad del mundo concreto, material: "Con el dedo tienta la pared interior de un mundo cerrado, de una matriz que lo protege" (p. 153). En "Jaula de un solo lado" (GC, p. 109), el narrador se pasea por el campo y encuentra una herramienta abandonada. En varias ocasiones clava sus dientes en la tierra y, en seguida, aparece un pájaro que se posa junto a las púas de hierro. Asombrado, el narrador comenta: “'Tenia todo el campo abierto a su disposición y sin embargo prefería inmovilizarse ahí, y mirar a través de los alambres! Por lo visto le gustaba sentirse prisionero y se inventaba una jaula" (p. 110). El sim. bolismo del relato es evidente: el pájaro, que niega su capacidad de volar para quedarse junto a la rígida hilera de púas, representa al hombre que niega su libertad intuitiva para encontrar la falsa seguridad de los conceptos racionales. Sigue siendo esencialmente libre, pero sacrifica la posibilidad de elegir, para tener la sensación de una vida segura e invariable.

\section{La libertad y el error}

Un tema que aparece frecuentemente en la obra de Anderson Imbert es el del héroe, el ser excepcional, que sale triunfante a pesar de los obstáculos que limitan al hombre ordinario; piénsense, por ejemplo, en el protagonista de "Patricio O'Hara, el libertador" (G, p. 223), o en Heracles de "Dodecafonía" (GC, p. 11). Pero, si el hombre es de veras libre, como sostiene Karl Jaspers, no puede eliminar la posibilidad de un error, no hay nada que asegure que su ideal heroico no sea falso o equivocado. Cuando se deja atraer por una meta egoísta y pusilánime, puede quedar atrapado, sin libertad, como el "caballero animoso" de "Melusina y su serpentario" (GC, p. 90). El héroe de este relato entra en un bosque misterioso y persigue a la bella Melusina con la idea de poseerla sexualmente. Ella se deja capturar y van a un palacio encantado donde hacen el amor incesantemente. Hastiado al fin, el caballero anuncia su deseo de salir del palacio, pero al atravesar la puerta, cae al patio, convertido en una culebra "corta, gorda y fláccida", símbolo de su impotencia sexual y de su libertad malgastada. Semejante situación se observa en "Pejesapo" (L, p. 119), donde un profesor de literatura se deja atrapar sexualmente por una de sus admiradoras.

El problema de la libertad se presenta más filosóficamente en "Un santo en las Indias" (G, p. 136). Esta obra, como indica el subtítulo-"Juguete para un teatro existencialista" - se basa en la idea de que "la existencia precede a la esencia", lo cual significa que la vida no está determinada a priori, sino que el hombre es libre para crear su propia existencia. En el momento de elegir, sin embargo, rechaza las otras elecciones posibles y tiene que aceptar las consecuencias de su elección; ya ha formado su "esencia". Por eso, cuando Fray Francisco le ruega a un anciano misterioso, que más tarde resulta ser el Diablo,

${ }^{24}$ Karl Jaspers, The Perennial Scope of Philosophy (New York, The Philosophical Library, 1949), p. 72 . 
que le de el poder de ser un santo y de llevar una vida exenta de pasiones pecarninosas, el anciano le responde: “¿De veras es eso lo que quieres? Piénsalo bien. Si fueras santo ya no podrías cambiar. Serías santo eternamente" (p. 161). Fray Francisco insiste, y su deseo está otorgado. Se hace santo y lleva una vida vacía, sin la necesidad de escoger entre el bien y el mal, porque, en efecto, ya ha escogido. Cuando muere al fin, está condenado para siempre al Infierno de las Ideas Puras, es decir, a la Nada.

También el solipsismo tiene unas poderosas consecuencias para la libertad de las personas. Mientras crean la realidad por medio de sus pensamientos y percepciones, son libres; pero enconces tienen que vivir la realidad creada. En "La lluvia" (G, p. 234), el personaje se encuentra en una situación extraña: afuera la luz del sol brilla sobre la aldea i tranquila, pero dentro de la habitación la lluvia cae copiosamente. Cuando la habitación comienza a inundarse, el hombre nada de un lado a otro, 'mirando horizontalmence por la ventana, "como un pez desde su acuario" (p. 235). Al fin, el agua liega al cielo raso, donde el hombre muere ahogado. Aunque contradiga las reglas del sentido común, el cuento puede explicarse fácilmente en términos de lo que hemos visto en este estudio. Porque la lluvia cae solamente dentro de la habitación, tiene que ser el producto del solus ipse, de la conciencia propia del protagonista. Puede representar su tendencia a refugiarse, tal vez por el miedo, en el mundo subjetivo de la inconsciencia; o, puesto que el agua es un símbolo femenino, puede representar de nuevo el anhelo de retornar a la paz del seno maternal. La imagen del pez en el acuario represenca su separación de la realidad exterior. En este caso no hay una sugestión de regeneración espiritual, porque el hombre se desintegra totalmente en la realidad demasiado subjetiva que él mismo ha creado. "El sofá" (L, p. 184) también presenća la historia de un hombre que está atrapado en su propia realidad, represent́ada por el sofá y por el deseo de venganza.

\section{CONCLUSION: ¿ESPERANZA O NIHILISMO?}

Después de examinar algunos de los elementos más importantes de la obra de Anderson Imbert, hemos llegado al momento de intentar una definición más o menos completa de su "visión del mundo". Después de todo, pues, ¿es su intención mostrarnos una vida productiva, donde el futuro ofrece la esperanza de un mundo mejor; o quiere ofrecernos la visión de un mundo caótico, donde todos los esfuerzos del hombre terminan en la nada? Con respecto a este punto, los críticos no están completamente de acuerdo. La mayoría de los escritores sí

\footnotetext{
${ }^{25}$ Basándose en oòras como "El hijo pródigo", "Fantomas salva al hombre" y "Un santo en las Indias", Isabel C. Ruiz sostiene que "la vida (en la obra de Anderson Imbert) es una maldición y no vale la pena de ser vivida", y "la muerte es un viaje, un transitar hacia el Ser absoluto, hacia donde el hombre se fundirá en el metal de la Nada"; Homenaje, p. 127. Para Gaivironski, los personajes de Anderson Imbert quedan indecisos "ante la alternativa de integrarse al mundo o rechazarlo. Cuando han elegido el camino se comportan cono seres pasivos, débiles ante los embates de la dura realidad o de la fantasía alucinante. Son incapaces de dominarlos. Se parecen al leve Pedro: una ráfaga de viento basta para destruirlos"; Op. cit., p. 122. Por otra parte, y más cerca de lo que hemos dicho en este estudio, Alfredo A. Roggiano afirma que "En el arte de Anderson Imbert el hombre impide que las cosas lo devoren, porque el hombre es, en última instancia, el inventor de su propia realidad"; en
} 
concuerda, no obstante, en que el concepto de libertad, tal como se presenta en su obra, amplifica la zona de las acciones posibles. Pero, como ha observado Fernando Aínsa: "La conquista de una dimensión amplia de la realidad no sirve de nada si no hay una fe que rompa el círculo de una lógica fatalista" ; ${ }^{26}$ en otra parte: "Todo lo que se ha conquistado en una dimensión (lo sobrenatural integrado de diversos modos a la realidad subvertida) se pierde en la dimensión de la fe."271 ¿Para qué sirve, en efecto, adquirir una nueva libertad de actuar, si sólo resulta en la creación de un mundo sin sentido, que está "encerrado y condenado al mismo tiempo"? Parece justificáda la observación de Aínsa, porque en Los domingos del profesor, el mismo Anderson Imbert ha escrito: "En estos últimos años es esta idea del sentido del mundo lo que está en crisis... A nadie consta que el universo tenga un destino. Sí sabemos, en cambio, que el universo no necesita de nuestra compañía. Somos prescindibles" (p. 104).

No cabe duda de que muchos cuentos presentan este aspecto pesimista de la visión de nuestro autor. Su actitud parece ser, esencialmente, la de un agnóstico: Dios existe y de una manera u otra ha creado el universo, pero esto no implica que Dios sea omnipotente, ni que se preocupe por el bien del hombre. En "Los ojos cerrados" (GC, p. 84), por ejemplo, Dios es ciego; sólo ve por los ojos del hombre. En "Los cuentos de Satán" (G, p. 86), y en "El sol" (GC, p. 18), Dios es una especie de demiurgo impotente que depende de sus propias creaciones; y en “Dios se justifica" (GC, p. 139), Dios está obligado a justificar sus actos ante la crítica de los seres humanos.

La idea de una vida sin sentido se encuentra en muchos relatos, como "Lógica de maniáticos" (GC, p. 113), donde se concibe el universo como un gran "huevo" cerrado. Y en "Arquitectura" (S, p. 136), el protagonista trata vanamente de descubrir el secreto de la vida antigua, y se compara a Peer Gynt, cuando arranca las capas de una cebolla y no encuentra el corazón. La conclusión: "La cebolla - el mundo-es una nada muy envuelta" (p. 137).

A pesar de estos ejemplos, y a pesar de las palabras del autor en el ensayo citado, la tarea de presentar la "intención cristalizada" en la visión de Anderson Imbert no sería completa si no mencionáramos también algunos de los cuentos de índole más optimista. A esta categoría pertenecen todos los cuentos que afirman la libertad del hombre. Y otro ejemplo notable que no hemos mencionado todavía se halla en|"Las'manos" G, p. 81), donde el héroe busca "el arcángel sin alas que conoce todos los secretos". Céspedes se introduce como un hombre excepcional, distinto de sus colegas más prosaicos: "Se abrió la puerta y por un instante la luz plateada de la tarde flameó sobre los hombros..."; más tarde el narrador comenta: "Céspedes era como el viento: si le hablábamos se nos iba con la voz." Para Cirlot, la luz, como la de la primera descripción de Céspedes, y también el

el Prólogo de Los domingos del profesor, Op. cit., p. XXVII. Evelyn Picón Garfield también declara: "A pesar de los frecuentes temas de incongruencias, fracasos y desilusiones, la visión de la vida de Anderson Imbert no nos parece negativa"; Homenaje, p. 166.

${ }^{26}$ Fernando Aínsa, "Modos de lo sobrenatural|en Anderson Imbert: 'Ensayo de una revuelta del contorno' ", en Homenaje, p. 362.

${ }^{27}$ Ibid., p. 360 . 
viento, son símbolos de la superioridad espiritual ${ }^{28}$ Céspedes representa así el hombre de gran fuerza espiritual que busca una meta ideal. El arcángel, en cambio, representa la sabiduría divina - "conoce todos los secretos"alas", lo cual sugiere que su sabiduria tienelímites, que no es omnisciente. Sugiere que no puede "volar", porque le falta el espíritu creador, intuitivo. ${ }^{29}$ Así, cuando Céspedes caza al arcángel y, en la última ocasión no lo suelta, muere con las manos arrancadas de un tirón. Pero triunfa en su muerte, porque el "arcángel sin alas volvió humillado a su reino, con manos de hombre prendidas para siempre a sus espaldas celestes" (p. 82). Ya tiene "alas" el arcángel: las manos de hombre, eterno recuerdo del valor del hombre, cuyo espíritu es necesario para completar la sabiduría divina.

El último cuento que se examinará en este estudio es "El hijo pródigo" (G, p. 41), y es tal vez el más útil de todos para llegar a un entendimiento de la visión de Anderson Imbert. El asunto se basa en la historia bíblica; Daniel es el hijo que se ha quedado en casa, y José es el pródigo que vuelve después de haber malgastado su fortuna en otras tierras. José es otro buscador, que pretende hallar una especie de "Centro" desconocido, que él define como "un sitio enorme, enorme, nunca visto ni sospechado" (p. 46). Corre mucho mundo y cree haber entendido varias cosas importantes. Descubre, como hemos anotado, que todos los hombres son un mismo hombre. Pero no ve, como Jung y muchos otros que creen en el concepto de la conciencia colectiva, la importancia del "yo" dentro de la colectividad. Para José, la importancia del hombre colectivo destruye el valor del individuo. Y este hombre colectivo, del cual todos los hombres somos una parte insignificante, constituye una totalidad cuyos límites nunca pueden ser traspasados. Por eso, el hombre no hace nada nuevo: sólo da vueltas dentro de los límites de lo ya creado. A pesar de la falta de novedades, el universo no es un conjunto armonioso: al contrario, "si pudiéramos ver, de un solo vistazo, todas las estelas que dejan las trayectorias de las cosas, veríamos el desorden más horroroso" (p. 51). Dios existe, pero merece nuestra lástima, porque "su existencia está tan perdida en el caos como la nuestra" (p. 51). De ahí que el mundo sea "un desierto de sal, estéril y sin salida" (p. 51), y la vida, solamente "chapoteo en el fango. Fango agitado. Nada más" (p. 47).

Hemos dejado hasta el último este relato porque contiene, indudablemente, todos los aspectos más negativos de la visión que vamos examinando. Pero también contiene, si no una solución, por lo menos una explicación y una esperanza. Lo que se explica no es el sentido de la vida, sino la causa de tanto pesimismo. Después de ver sus ideas tan poco optimistas, es evidente que José es un racionalista frustrado, que hace de la razón un ideal imposible. Es un racionalista cuyo gran ideal es entenderlo todo, y cuando fracasa inevitablemente, termina en un nihilismo absoluto. Es como la "bestia

${ }^{28}$ Cirlot, Op. cit., p. 179 y p. 353. 355 .

${ }^{29}$ Según Cirlot, las alas simbolizan espiritualidad, imaginación y pensamiento; Op. cit., pp. 354 - 
paradójica" de Machado, un hombre que utiliza los conceptos puros de la razón para concebir un mundo inexistente, y luego declara: "Ya estoy en el secreto...todo es nada".

Entonces, al lado de José está su hermano Daniel. José nunca lo entiende, tal como Dédalo nunca pudo entender al intuitivo Icaro. Para José, su hermano es un "niño grande", un tonto, y solamente por eso posee todavía su ingenua fe en la vida y en sí mismo. Pero el lector, que no está cegado por un racionalismo exagerado, sí puede ver la esperanza que Daniel representa. Como Jacobo, "el niño tonto"- que solamente es tonto desde el punto de vista racional del farmacéutico y su mujer -, Daniel triunfa sobre sus límites y encuentra la felicidad. El suyo no es un optimismo ciego-reconoce el mal, admite que la victoria es difícil y, a veces, imposible -, pero no se rinde al pesimismo. Daniel, pues, es el verdadero racionalista, que ve el bien junto al mal, para quien la vida se mueve armoniosarnente, "como una danza, como un ejército". Y, en los ojos de Daniel, es José el que es el niño, el inmaduro: "Eres el niño de siempre, sin madurez. Mimoso, asustadizo. Ahora veo que tu viaje no te cambió. La vida te ha golpeado, eso es todo. Pareces un niño hinchado a golpes" (p. 48). Al final, cuando José queda dormido, Daniel lo carga en los brazos, moviéndose lentamente, con cuidado, para no despertarlo y prolongar su dolor. Parece reconocer, así, que a veces es mejor dormirse, que es mejor cerrar los ojos, admitir los límites y no pedir demasiado a la vida. He aquí el verdadero racionalismo.

Con esto terminamos la tarea de recorrer el gran círculo que representa la totalidad de los cuentos de Anderson Imbert. Hemos examinado la cuaternidad de los libros, deteniéndonos de vez en cuando en algunas de las obras más representativas, pensando siempre en el Centro, que es la visión del mundo que nos ofrece su autor. Hemos visto, en fin, que esa visión, como todo intento de entender la vida profunảamente, contiene varios elementos que se oponen, pero sin que se destruya la unidad esencial. No cabe duda de que el mismo Anderson Imbert, como José su extraordinario hijo pródigo, es a veces un gran racionalista que mira a la vida a través de la lupa de su intelecto y ve las imperfecciones y los absurdos. Es igualmente evidente, sin embargo, que también hay dentro de nuestro autor un gran niño, un niño tonto, que cree en la magia y se ríe de las ideas pesimistas. El resultado de este conjunto de elementos afines y opuestos es una visión equilibrada que une lo racional y lo irracional, lo consciente y lo inconsciente, para constituir una especie de "mandala literaria", un símbolo artís tico de la verdadera totalidad psíquica.

State University of New York, Albany

ARMAND F. BAKER

${ }^{30}$ Antonio Machado, Obras: poesía y prosa (Buenos Aires, Losada, 1964), “Proverbios y cantares", CXXXVI, xvi, p. 215. 